\title{
Estimation of water surface elevation on inundated area using satellite based information
}

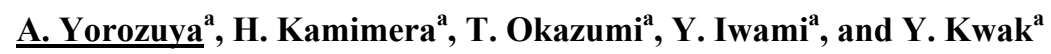 \\ ${ }^{a}$ International Centre for Water Hazard and Risk Management under the auspices of UNESCO (ICHARM) \\ Public Works Research Institute, Japan \\ Email: yorozuya@pwri.go.jp
}

\begin{abstract}
Recently, water-related disasters have become frequent in the globe; e.g., the large flooding in 2011 at Chao Phraya Basin in Thailand caused considerable damage. Not to repeat such a catastrophe, a risk reduction strategy needs to be considered with a comprehensive risk assessment as well as appropriate information. Also the climate change is one of the important factors that need to be included in the risk reduction strategy. Therefore, actual phenomena should be analyzed based on the past events. Sooner or later, numerical estimation should be conducted with verifying the past event. Therefore, as the first step of constructing the risk reduction strategy, the most fundamental information is water surface elevations on inundated area at the points of interest. This paper aims to obtain the water surface elevation based on observed value.

The present study describes processes to estimate the water surface elevation on inundated area applying satellite based information. As targeted area, Lower Mekong Basin (LMB), which is frequently flooded area, was selected. Firstly, eight days composite data set of Moderate Resolution Imaging Spectrometer (MODIS) was applied for obtaining inundated area with calculating Modified Land Surface Water Index (MLSWI). This is the index to identifying water bodies, which is originally proposed by the authors. MLSWI from 2002 to 2012 in the part of LMB was well examined, flood types were then classified to illustrate flood phenomena. Secondary, with combining Digital Surface Model (DSM) obtained from the Shuttle Radar Topography Mission (SRTM) as well as the inundated area with MLSWI, horizontal distribution of the water surface elevation (WSE) with the selected types of flooding was estimated. Tuning up of the MLSWI with local gauge information is necessary for better estimation. Finally, an appropriate water surface profile, which conforms to hydraulic judgment, was obtained.
\end{abstract}

Keywords: Inundated area, Water surface elevation, Satellite information, Lower Mekong Basin 


\section{INTRODUCTION}

Recently, water-related disasters have frequently occurred in the globe; e.g., the large flooding in 2011 at Chao Phraya Basin in Thailand caused considerable damage and sufferings to the people in the basin. Not to repeat such a catastrophe, a risk reduction strategy needs to be considered with a comprehensive risk assessment as well as appropriate information. The most fundamental information, for this purpose, is the location of water body as well as water depth at points of interest, especially on inundated areas during flooding.

For the purposes of estimating water depths on floodplains where local Digital Surface Model (DSM) is not well established; e.g., developing countries, a numerical simulation with Shuttle Radar Topography Mission (SRTM) has frequently been applied because of sufficient availability and easy accessibility. Actually, many numerical analyses with SRTM have already been conducted with different scales, a region based scale such as Asia-Pacific (e.g., Kwak et al., 2012b), a water shed scale (e.g., Sayama et al., 2013), and a part of river channel (e.g., Yamazaki et al., 2012). On the other hand, Panchromatic Remote-sensing Instrument for Stereo Mapping (PRISM) operated by Japan Aerospace Exploration Agency (JAXA) has already observed most of the part of the globe, and can produce PRISM DSM with a stereo matching processing. Though it has jitter noises with roughly 5 meter wave height, 10 meter grid size is attractive enough to apply in an inundation simulation. Actually, Yorozuya et al., (2013) proposed a method of modifying the PRISM DSM to be implemented to the simulation with smoothing the noises. Using those available DSM, the objective of this paper is to estimate the water depth using the numerical simulation. In this analysis, some uncertainties cannot be neglected in the poorly gauged basins since the simulation depends on the initial and boundary conditions.

Another method to estimate water bodies is application of satellite based information. For example, Alsdort et al., (2007) introduced the method with image sensor, such as Landsat, Moderate Resolution Imaging Spectrometer (MODIS), and SPOT, and also introduced the one with Synthetic-Aperture Radar (SAR). They mentioned those techniques are good enough, though there are some limitations on usages. On the other hand, Kwak et al. (2011) developed an index to identify water bodies based on MODIS information, which is Modified Land Surface Water Index (MLSWI), and estimated water bodies on a floodplain. Later, Kwak et al. (2012a) revised MLSWI and applied it to Chao Phraya river basin.

The final goal of this paper is estimation of water depth based on observed information in Lower Mekong Basin (LMB) in Cambodia. For this purpose, we estimated water bodies on the floodplain with MLSWI. Thereafter, we obtained water surface elevation (WSE) by combining SRTM and MLSWI.

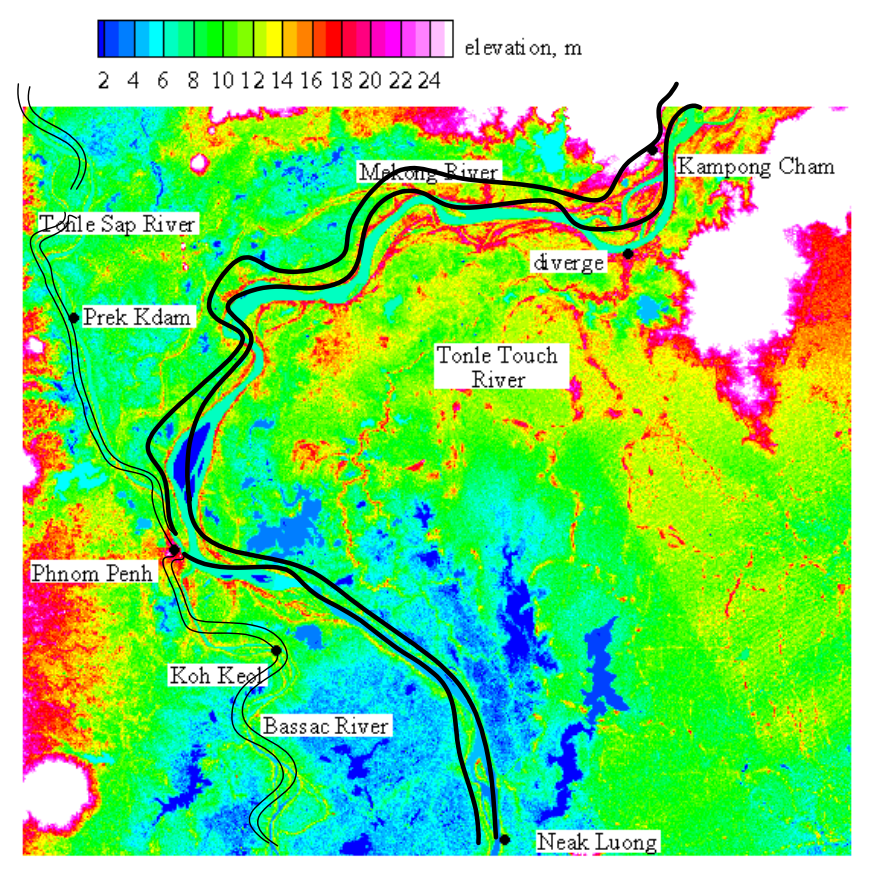

Figure 1. Location of targeted area with the range of $100 \mathrm{~km} \times$ $90 \mathrm{~km}$.

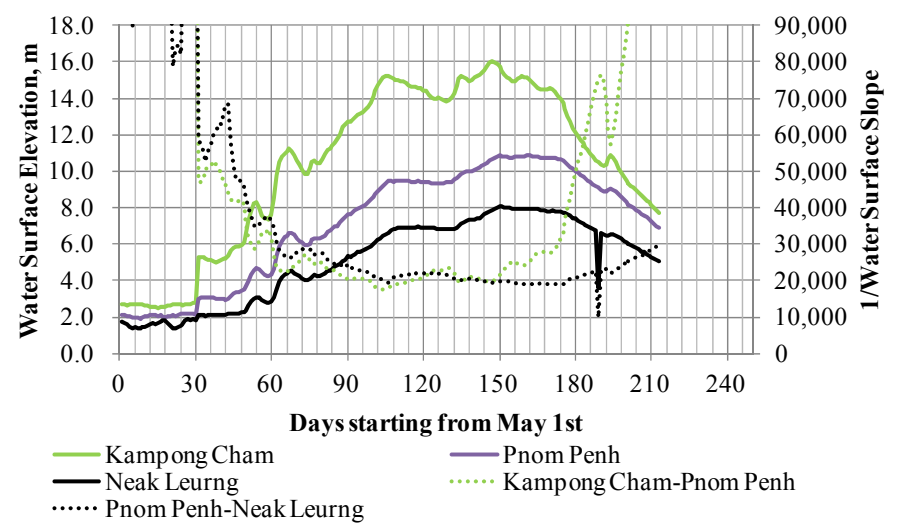

Figure 2. Timely change of water surface elevation as well as water surface slope. 


\section{TARGET AREA}

The target area of this study is LMB in Cambodia shown in Figure 1. The Mekong River originally starts from Tibet, and goes through China, a border between Myanmar and Lao PDR, another border between Lao PDR and Thailand, Cambodia, Vietnam, and finally flows into South China Sea. The Mekong River converges with the Tonle Sap River at Phnom Penh, and diverges from the Bassac River at the same location. The Tonle Touch River is originated from the Mekong River at the point of diverge, just downstream of Kampong Cham in Figure 1. At this point, the Mekong River has a width of about 1,200m, when the Tonle Touch River has about 70m. There are a few water-level gauges in this area, e.g., Kampong Cham, Phnom Penh and Neak Luong along the Mekong River. Other gauges are located at Prek Kdam along the Tonle Sap River as well as Koh Keol along the Bassac River.

Figure 2 shows timely changes of water surface elevations as well as water surface slopes at Kampong Cham, Phnom Penh, and Neak Luong. The water surface slopes were calculated between Kampong Cham and Phnom Penh, and between Phnom Penh and Neak Luong. The water level at Kampong Cham started from $2.67 \mathrm{~m}$ and reached the maximum peak of $16.02 \mathrm{~m}$ on 25 th of September (which is 148 days from May 1st). The average peak between 22nd and 30th of September was $15.74 \mathrm{~m}$ at Kampong Cham, and $7.84 \mathrm{~m}$ at Neak Luong. Both water surface slopes around this period were about 1/20,000.

\section{METHOD}

To estimate WSE, the following three steps are required: (1) estimation of water body distribution, (2) smoothing of DSM to obtain modified DSM, and (3) estimation of WSE based on the water bodies and the modified DSM.

\subsection{Estimation of water body distribution}

To estimate water body distribution in this target area, 8-day composite information obtained by MODIS and MLSWI were applied. MLSWI is basically the index to identify muddy water by using band 2, which is near-infrared (NIR), and band 7, which is short-wavelength infrared (SWIR), with the following equation:

$$
M L S W I=\frac{A_{S W I R}-R_{N I R}}{A_{S W I R}+R_{N I R}}
$$

where $A_{i}$ and $R_{i}$ are absorption rate and reflection rate, respectively. Since these two rates relate as $A_{i}=1-R_{i}$, MLSWI can be determined. Based on MLSWI and information from MODIS, an MLSWI distribution can be calculated. MLSWI determines surface types, such as surface water, muddy water, flood water, soil, vegetation, snow and cloud (e.g., Kwak et al., 2012a). To distinguish water bodies (e.g., surface water, muddy water and floodwaters) from the rest of the surface types, a threshold value should be determined.

This threshold value is usually between 0.5 and 0.8 , though it should be defined more specifically based on field observation with a spectrometer or by maintaining consistency among observed values of WSE, DSM and an MLSWI distribution. The authors selected the latter approach since there are local gauge stations that can provide necessary data and the former requires field survey during flooding.

The estimation process begins with resampling of the MLSWI distribution to obtain the same grid size with DSM. Secondary, an area of DSM which is less than the target height is determined. Here, the target height is the water surface elevation obtained by the local water gauges during the target time period. Another area of MLSWI which is more than the target value is determined. When both areas are matched, the target MLSWI value is defined as the threshold value. The area should be an appropriate size that allows the water surface elevation to be constant within the area.

\subsection{Smoothing of DSM to obtain Modified DSM}

DSM obtained from SRTM has jitter noises. Such noises should be eliminated for better estimation of water surface elevations. Goldstein and Werner (1998) applied the high pass filter with FFT to smooth DSM. On the other hand, Yorozuya et al. (2013) modified PRISM-DSM to eliminate jitter noises. Firstly they selected a window to obtain a least square plain. Then, structures, which include levee, embankment, houses, etc, are determined by subtracting the plain from the original DSM. Thereafter, moving to a next window overlapping part of the area, the same process is operated to obtain the plain and the structure. After repeating the process to cover the whole target area, moving averaged values from windows are obtained for both the plains and the structures. Finally, the moving averaged structure placed on the averaged plain, modified DSM constructed. If the size of a window is too large, local undulations disappear. For example, if 
the size of window is same as that of whole domain, only flat surface appears without any undulations. Contrarily, if the size of a window is too small, the undulation of the plain may be largely affected by noises. Therefore, the size of a window should be carefully selected comparing with photos or other information. In this study, the data processing to obtain the modified PRISM-DSM was applied to SRTM DSM to obtain smooth DSMs. Also SRTM DSM was resampled with the nearest neighbor to $100 \mathrm{~m}$ grid size.

\subsection{Estimation of Water Surface Elevation}

Similar to the process used to obtain modified DSM, the moving average process was applied. Every single point except edges in a window was examined with a neighboring point. If the threshold value, determined in subsection 3.1, lied between two MLSWI values, the point of interest was recognized as a border between the wet and dry areas. Other seven neighboring points were examined as well. Once borders were recognized, assuming that MLSWI and DSM had a linear relationship, an elevation from DSM was calculated with inputting the exact threshold to the linear function. The same data processing is conducted for every point, the elevations are averaged, and the averaged as well as standard deviation $(\sigma)$ value is assigned as the WSE in the single window. Finally, an averaged-smooth water surface is obtained after moving averaging in the whole domain area. Similar to smoothing of DSM, the size of the window is carefully considered. For example, when the window is small and the target area is wide floodplain, the borders cannot be recognized in the single window. Hence, the elevation cannot be determined. Contrarily, when the window is large and the target area is sort of valley type geometry, water body from different sources or that in other valley is recognized as single values. As a consequence, the standard deviation might be larger.

\section{RESULTS}

\subsection{Zoning of Inundated area}

Figure 3 indicates the MLSWI distribution with averaging of 483 composites, which are collected for about 11 years from 2002 to 2012 . The figure shows the northern half of LMB including Kampong Cham and Phnom Penh compared with Figure 1. As it shows, the areas around the Mekong River and the Tonle Sap River have most likely higher values compared with others. Also this map is similar to an inundation map issued by the Mekong River Commission (MRC),

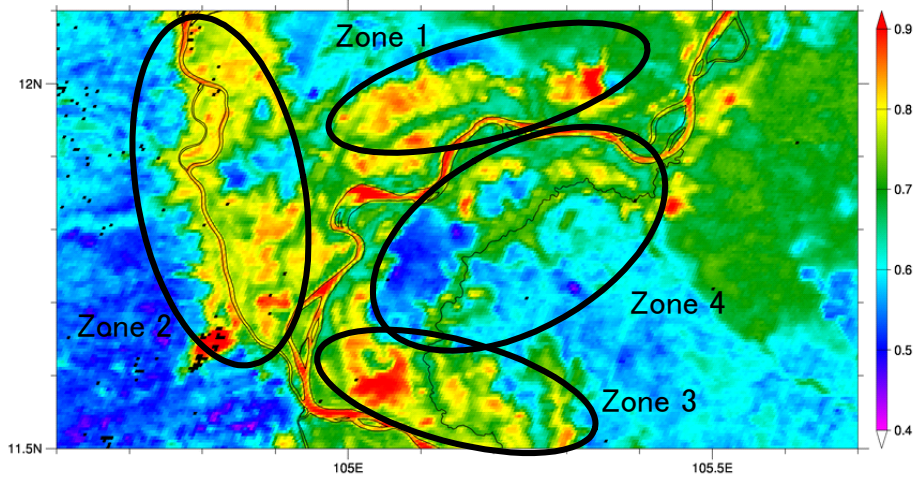

Figure 3. MLSWI distribution with averaging of 483 composites from 2002 to 2012. Figure shows northern half of LMB. though it is not discussed in this paper because of space limitation. Also, Figure 3 indicates four zones, which were classified based on Figure 3, timely changes of the MLSWI, and the location of colmatage system, which is an irrigation canal system in Cambodia. Again the latter two pieces of information are not described in detail in this paper because of space limitation. Zone 1 is located in the right side of the Mekong River and surrounded by natural levees and many colmatage canals. The inundated water body by MLSWI starts to appear even before the water surface in the Mekong River is lower than the natural levees. Zone 2 is an inundated area along the Tonle Sap River. Hence, the area is affected by the Tonle Sap Lake. Zone 3 is on the left side of the Mekong River and has similar characteristics with Zone 1. Zone 4 is on the left side of the Mekong River and the Tonle Touch River flows at the center of the zone. In this area, most of floodwaters come along the Tonle Touch River, or overflows around the diverge area when the flood flow is large. One of the purposes of this paper is estimation of water surface elevation on the floodplain. Based on the above discussion, regarding Zones 1 and 3, the water bodies on the floodplain are well connected to that of the Mekong River, though timing of the elevation changing might be different. Therefore, the elevation can represent that of the Mekong River. Therefore, as long as the water surface along the Mekong River can be estimated, the elevation on the both zones can also be estimated. Regarding Zone 2, the hydraulic phenomena might be complicated, since the flood flow is dominated by that of the Tonle Sap Lake. Regarding Zone 4, the elevation is dependent on the flow capacity of the Tonle Touch River as well as water discharge diverged from Mekong River. 


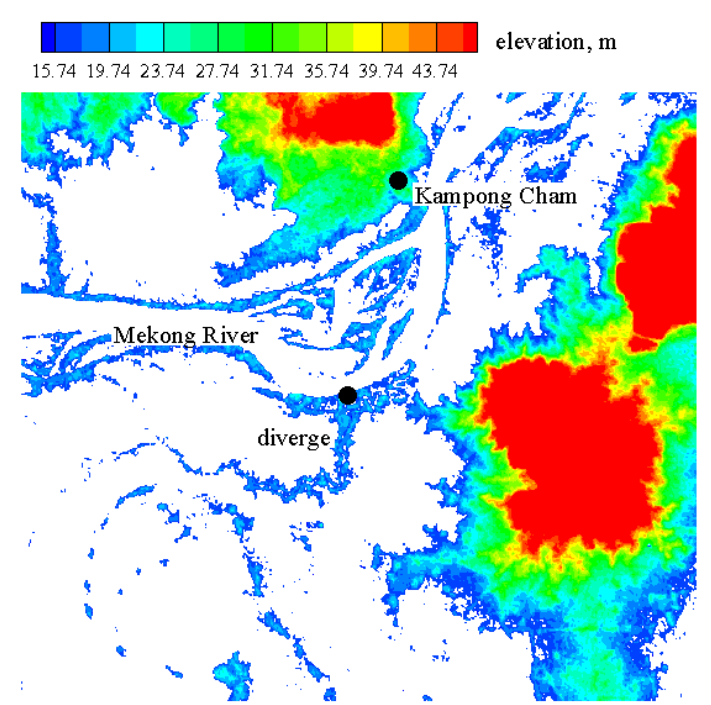

Figure 4. DSM around Kampong Cham $(35 \mathrm{~km} \times$ $39 \mathrm{~km}$ ). Only above $15.74 \mathrm{~m}$ is shown.

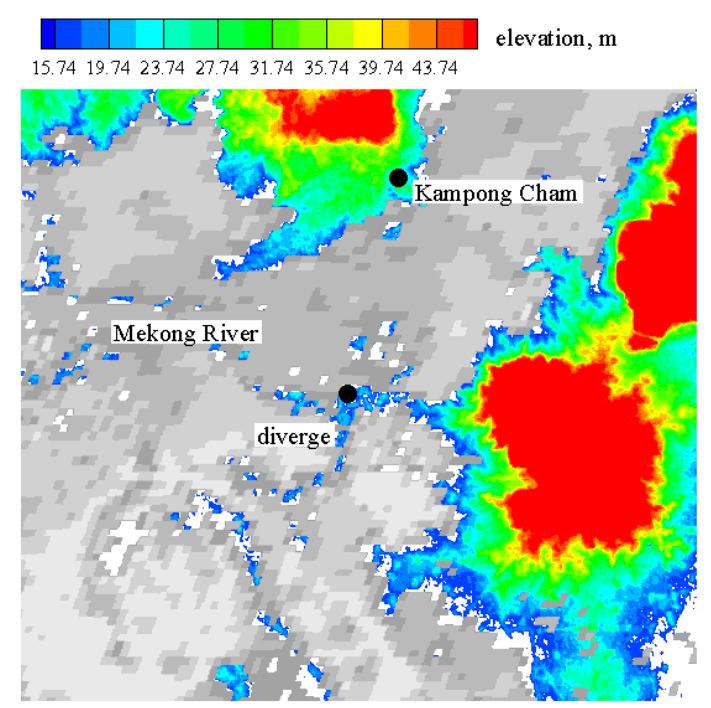

Figure 5. DSM and MLSWI Only above 0.64.

\subsection{Water Surface Elevation}

Distribution of the WSE was estimated by the method described in section 3 of this paper. The targeted flood event is flood on September of 2011, which is one of the largest floods in recent years. Mainly 8-day composite values between September $22^{\text {nd }}$ and $30^{\text {th }}$ were selected. The water surface elevation obtained by the local water-level gauge at Kampong Cham was the highest of $15.74 \mathrm{~m}$ as described in Figure 2. Based on the information, Figure 4 is obtained from DSM with only showing the values, which are more than $15.74 \mathrm{~m}$ around the Kampong Cham area with the size of $35 \mathrm{~km} \times 39 \mathrm{~km}$. Similarly, Figure 5 shows MLSWI which is more than the threshold value of 0.64 as well as same DSM with Figure 4. Comparison indicates that overall shape is very similar. Also the natural levee around the point of diverge indicates higher value by the DSM, and actually MLSWI indicates the dry area. However, some natural levees in middle of the Mekong River indicated wet area, though DSM shows the value higher than $15.74 \mathrm{~m}$. Though this small difference or inconsistency appears, this overall comparison is good enough to determine the threshold value. It may be noted that Figure 5 is the result of trial and error processes to determine the threshold value of 0.64. After estimating the whole domain of the targeted area, the distribution of the WSE was superimposed on Figure 1 including river lines of the Mekong River, the Tonle Sap River, and the Bassac River, as shown in Figure 5. The WSE has no value when MLSWI is smaller than the threshold value, which indicates the dry area.

As Figure 6 indicates, the WSE shows higher value around the Kampong Cham area. After flood water flows this area, it widely spreads to Zone 1 and Zone 4. Along the Mekong River from Kampong Cham to Phnom Penh, the altitude of water surface gradually goes down, though it has a bit higher value around confluence point. Because of the complexity of flow around this area or because of difficulty of estimation, the WSE is kind of difficult to understand around this area.

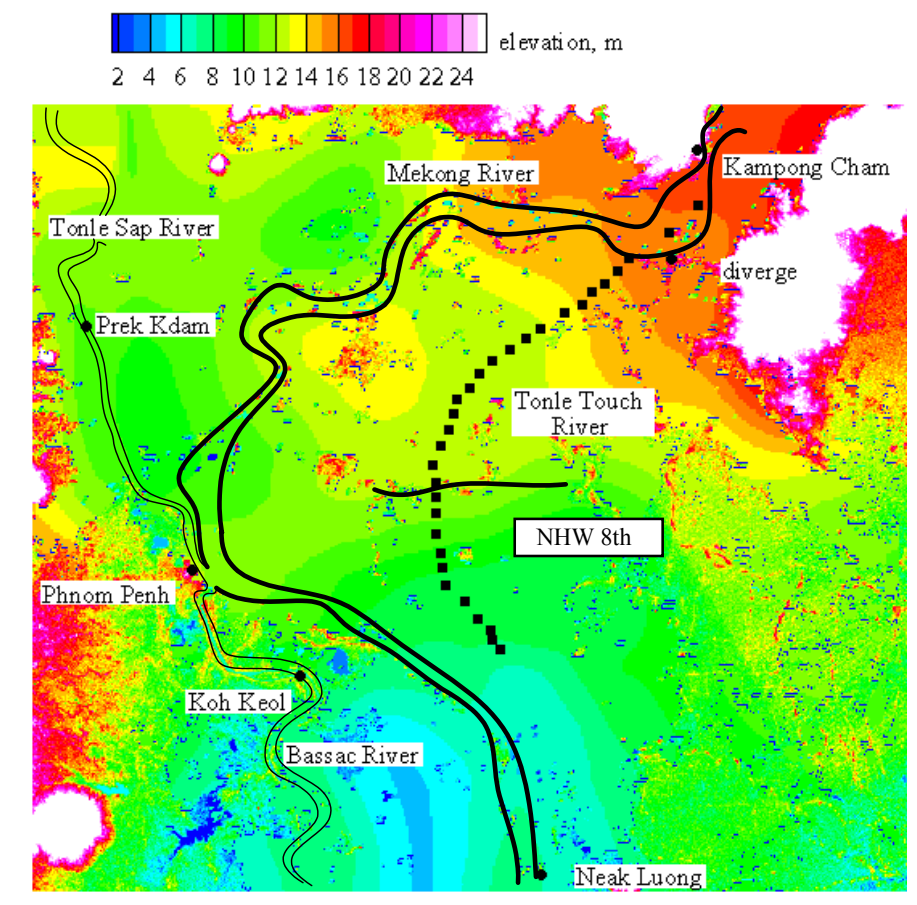

Figure 6. Distribution of water surface elevation in LMB with the range of $100 \mathrm{~km} \times 90 \mathrm{~km}$. 
Another difficulty to interpret this figure is longitudinal distribution of WSE along the Tonle Sap River. As it mentioned before, the flow around the area, which was classified as Zone 2, might have complex flow pattern because of complicated system involving different flow system. Therefore, further study related to the flow in the Zone 2 and the Tonle Sap Lake need to be conducted separately. As flow goes down to downstream along the Mekong River from Phnom Penh, the WSE gradually falls down, which is reasonable. At the very upstream of the Bassac River, there is area where flood flow does not exist. It might or might not be true, but it should be recalculated with different threshold value using water level observation at Phnom Penh. Finally, the local maximum showing in the yellow color in between the Mekong River and the Tonle Touch River is difficult to understand. Since this place does not have any sources of water, local maximum of WSE cannot be located in this area. This kind of estimation error occurs because window size was not properly selected.

To discuss more in detail about the flow in Zone 4, the longitudinal WSE profile is described. In Figure 6, series of black square marks located along the Tonle Touch River. The WSE values, WSE \pm $\sigma$ and DSM from each single point of the marks were picked up; thereafter, Figure 7 was drawn as the longitudinal distribution originated from the most upstream mark. As it shows, the WSE starts to have slope about $1 / 7,000$ between 0 and $22,000 \mathrm{~m}$. Thereafter, it becomes almost flat between 22,000 and $44,000 \mathrm{~m}$. In the end, it becomes about

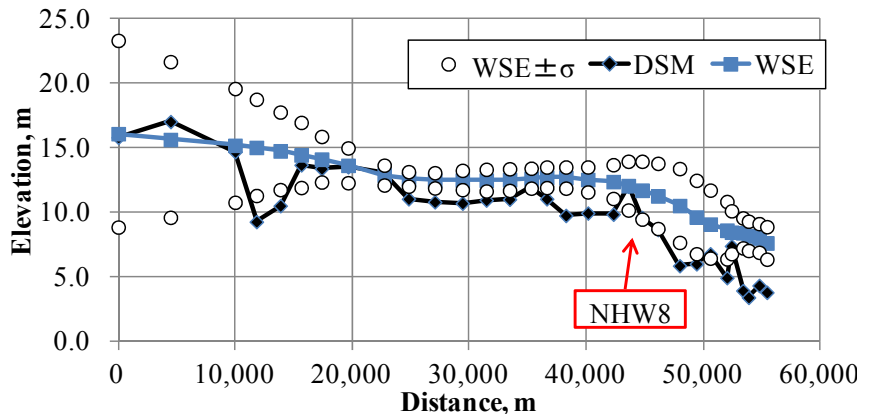

Figure 7. Longitudinal distribution of WSE, DSM and $\mathrm{WES} \pm \sigma$ along the Tonle Touch River. 1/2,600 between 44,000 and downstream end. As both Figures 6 and 7 indicate, there is the national high way 8 (NHW8) at this location. The NHW8 is the road embankment, where embankment height is about 4 or $5 \mathrm{~m}$ depending on the location. This load has about 20 bridges in this Zone 4; each bridge has about 100 $\mathrm{m}$ opening. Thus the flood water might be not fully, but partially blocked. Therefore, the water surface profile becomes flat at upstream side of NHW8 as Figure 7 indicates. This is one of the verification of the method described in this paper.

The adopted method estimated $16.10 \mathrm{~m}$ and $7.64 \mathrm{~m}$ at upstream and downstream end, respectively. As Figure 2 indicates, the WSE at Kampong Cham and Neak Luong are 15.74 and $7.89 \mathrm{~m}$ respectively. Actually, distance between the downstream end of Figure 6 and Neak Luong is about $20 \mathrm{~km}$. Therefore, 1-m height differences can be estimated between both points, since water surface slope in this reach is about 1/20,000 based on observed results as shown in Figure 2. Then, actual WSE at both points are 15.74 and $8.89 \mathrm{~m}$ respectively. Therefore, differences between estimation and observation at both ends are $0.36 \mathrm{~m}$ and $-1.25 \mathrm{~m}$, respectively.

Another important aspect is $\sigma$, which varied in different location. As Figure 7 indicates, standard deviations are much higher in the upstream side, though they are very small in the middle. Actually, geometry around upstream side has larger undulation than that of rest of area, since natural levee developed along the Mekong River. On the other hand, the geometry in the middle is much flatter since the area is in the middle of flood plain. As this figure indicates, since $\sigma$ in the middle is small, the window was adjusted to obtain the suitable results on the floodplain. From this point of view, the different size of widow has to be selected depending on the undulation, if the WSE needs to be obtained with similar size of $\sigma$.

\section{FURTHER STUDY AND CONCLUSION}

Several important points were described in the previous discussion for further study. Those insights are explained below.

To conduct the risk assessment, estimation of WSE using the satellite based information was discussed. Three steps are required for this purpose, such as calculation of MLSWI from MODIS data to obtain the water body distribution, obtaining of modified DSM after smoothing jitter type noises, and estimation of WSE using MLSWI and modified DSM.

Using MODIS information from 2002 to 2012 at Lower Mekong Basin in Cambodia, averaged MLSWI was calculated and inundation area was zoned based on flood types. 
By using the case of 2011 flooding at the end of September, the WSE was determined. Several difficulties were pointed out, such as the estimation method is not well enough to understand the complex flow field like Zone 2, which including the confluence and diffluence of flow as well as Tonle Sap Lake. Also size of the single window to very beginning of the moving averaging process sensitively affects to estimation of WSE. This paper tries to estimate the WSE with single size of the window in the whole domain, which includes wide floodplain, or valley surrounded by the natural levee. Actually, few difficulties were pointed out because of the window size. Certainly good estimation was obtained in the Zone 4 as shown in Figures 6 and 7, since appropriate size was selected, which is suitable to the geometry in the Zone 4.

One of the important further studies is installing an option to select the window size depending on the geography.

\section{ACKNOWLEDGEMENTS}

The authors acknowledge that the local gauge data were provided by the Mekong River Commission.

\section{REFERENCE}

Alsdorf, D.E., Rodriguez, E., and Lettenmaier, D.P. (2007). Measuring surface water from space, Rev. Geophys., 45, RG2002, doi:10.1029/2006RG000197.

Goldstein, R. M., and Werner, C. L. (1998). Radar interferogram filtering for geophysical applications, Geophysical Research Letters, VOL. 25, NO. 21, P. 4035, 1998. doi:10.1029/1998GL900033.

Kwak, Y., Park, J., and Fukami, K. (2011). Nation-wide Flood Risk Assessment Using Inundation Level Model and MODIS Time-series Images, Proceeding IEEE-IGARSS 2011, IEEE, pp.4395-4398.

Kwak, Y., Park, J., Yorozuya, A., and Fukami, K. (2012a). Estimation of flood volume in Chao Phraya river basin, Thailand from MODIS images coupled with flood Inundation level, the 32nd annual IGARSS symposium 2012, IEEE Geoscience and Remote Sensing Society, pp.887-890.

Kwak, Y., Takeuchi, K., Fukami, K., and Magome, J. (2012b). A new approach to flood risk assessment in Asia-Pacific region based on MRI-AGCM outputs, Hydrological Research Letters 6, 70-75.

Sayama, T., Tatebe, Y., Fujioka, S., Ushiyama, T., Yorozuya, A., and Tanaka, S. (2013). An Emergency repsonse-type rainfall-raunoff-inundation prediction for 2011 Thailand flood, Journal of Japan Society of Civil Engineers, Ser. B1 (Hydraulic Engineering), Vol. 69, No. 1, p. 14-29. (in Japanese)

Tadono, T., Shimada, M., Takaku, J., Murakami, H. (2012). Update calibration results of PRSISM and AVNIR-2 onboard ALOS 'Daichi', IEE International Geoscience and Remote Sensing Symposium, pp.5029-5032.

Yamazaki, D., Baugh, C.A., Bates, P.D., Kanae, S., Alsdorf, D.E., Oki, T. (2012). Adjustment of a spaceborne DEM for use in floodplain hydrodynamic modeling, Journal of Hydrology, Volumes 436?437, 2 May 2012, Pages 81-91, ISSN 0022-1694, http://dx.doi.org/10.1016/j.jhydrol.2012.02.045.

Yorozuya, A., Kwak, Y., Shiratori, A., and Fukami, K. (2013). Study on PRISM DSM application to inundation analysis and its modification method, Journal of Civil Engineers, Ser. B1 (Hydraulic Engineering), Vol.69, No.4, I_1549-I_1554. (in Japanese) 